Hydrol. Earth Syst. Sci., 17, 5097-5108, 2013

www.hydrol-earth-syst-sci.net/17/5097/2013/

doi:10.5194/hess-17-5097-2013

(c) Author(s) 2013. CC Attribution 3.0 License.

\title{
Quantifying mesoscale soil moisture with the cosmic-ray rover
}

\author{
B. Chrisman and M. Zreda \\ Department of Hydrology and Water Resources, University of Arizona, Tucson AZ, USA \\ Correspondence to: M. Zreda (marek@ @wwr.arizona.edu)
}

Received: 17 May 2013 - Published in Hydrol. Earth Syst. Sci. Discuss.: 5 June 2013

Revised: 19 November 2013 - Accepted: 20 November 2013 - Published: 17 December 2013

\begin{abstract}
Soil moisture governs the surface fluxes of mass and energy and is a major influence on floods and drought. Existing techniques measure soil moisture either at a point or over a large area many kilometers across. To bridge these two scales we used the cosmic-ray rover, an instrument similar to the recently developed COSMOS probe, but bigger and mobile. This paper explores the challenges and opportunities for mapping soil moisture over large areas using the cosmic-ray rover. In 2012, soil moisture was mapped 22 times in a $25 \mathrm{~km} \times 40 \mathrm{~km}$ survey area of the Tucson Basin at an average of $1.7 \mathrm{~km}^{2}$ resolution, i.e., a survey area extent comparable to that of a pixel for the Soil Moisture and Ocean Salinity (SMOS) satellite mission. The soil moisture distribution is dominated by climatic variations, notably by the North American monsoon, that results in a systematic increase in the standard deviation, observed up to $0.022 \mathrm{~m}^{3} \mathrm{~m}^{-3}$, as a function of the mean, between $0.06 \mathrm{~m}^{3} \mathrm{~m}^{-3}$ and $0.14 \mathrm{~m}^{3} \mathrm{~m}^{-3}$. Two techniques are explored to use the cosmic-ray rover data for hydrologic applications: (1) interpolation of the 22 surveys into a daily soil moisture product by defining an approach to utilize and quantify the observed temporal stability producing an average correlation coefficient of 0.82 for the soil moisture distributions that were surveyed, and (2) estimation of soil moisture profiles by combining surface moisture from satellite microwave sensors (SMOS) with deeper measurements from the cosmic-ray rover. The interpolated soil moisture and soil moisture profiles allow for basin-wide mass balance calculation of evapotranspiration, which amounted to $241 \mathrm{~mm}$ in 2012. Generating soil moisture maps with a cosmic-ray rover at this intermediate scale may help in the calibration and validation of satellite soil moisture data products and may also aid in various large-scale hydrologic studies.
\end{abstract}

\section{Introduction}

Quantifying area-average soil moisture at the mesoscale (2$1000 \mathrm{~km}$ ) is difficult because of the footprint or support volume (Western and Bloschl, 1999; Robinson et al., 2008) of current measurement methods. Satellite microwave sensors have a large $(3-50 \mathrm{~km})$ footprint, which may be too coarse a resolution for atmospheric and hydrological applications (Kerr et al., 2010). At the other extreme, in situ point measurements have very small support volumes (e.g., Robinson et al., 2008) that are likely not representative of the surrounding area (Zreda et al., 2012). Currently there is a gap in observational methods for measuring soil moisture at intermediate scales between point measurements and satellites pixels. This has stimulated research into area-average soil moisture monitoring using GPS surface feedbacks (Larson et al., 2008), distributed sensor networks (Bogena et al., 2010), and cosmicray neutron monitoring (Zreda et al., 2008, 2012). GPS receivers and cosmic-ray neutron probes provide a significant improvement in measuring area-average soil moisture, but their support volumes are still small when compared with the vastness sampled by satellite instruments. Distributed sensor networks may also have a relatively small footprint if they are installed over a small area and, if they are widely spaced, they act as point measurements, not necessarily representative of a study area.

There remains a need for a practical method to measure soil moisture at the scale between the footprint of a stationary COSMOS probe (600 $\mathrm{m}$ diameter) and satellite imaging (3$50 \mathrm{~km})$. COSMOS probes take advantage of the remarkable ability of hydrogen to remove neutrons created by cosmic rays at and near the land surface (Zreda et al., 2008, 2012; Desilets et al., 2013). In the absence of surface water bodies, the main reservoir of hydrogen is soil moisture. Hydrogen in soil moisture removes a fraction of neutrons from the soil and 
the atmosphere, and the neutron intensity above the land surface is inversely correlated with soil moisture content. The cosmic-ray method and stationary COSMOS probes are described in detail in Zreda et al. (2012).

Here, we describe the first systematic mapping of soil moisture with the use of a mobile cosmic-ray probe, called the cosmic-ray rover (Desilets et al., 2010). The cosmic-ray rover uses the technology of the COSMOS probe and thus has the same horizontal footprint $(600 \mathrm{~m})$, when stationary, and the same range in measurement depth $(12-76 \mathrm{~cm}$, but see discussion below) (Zreda et al., 2012). When used in a roving mode, the cosmic-ray rover allows for mapping of soil moisture over an area commensurate with a satellite pixel, thereby filling a spatial gap in soil moisture observations.

Using a cosmic-ray rover, we made 22 one-day surveys inside the Tucson Basin over an area $25 \mathrm{~km} \times 40 \mathrm{~km}$ in size and over a period approaching one year. We present results of neutron measurements and describe an exploratory approach to integrate these measurements with ancillary data to produce an enhanced soil moisture product. Section 2 introduces the geographic and hydrologic setting of the Tucson Basin. Section 3 outlines the cosmic-ray rover survey scheme and the conversion from neutron intensities to soil moisture. Section 4 describes the resulting cosmic-ray rover measurements with emphasis on the observed recurring spatial patterns and their predictability, and the paper concludes by estimating evapotranspiration in the Tucson Basin in 2012.

\section{Geographic setting of the Tucson Basin}

The study area is situated in an extensional basin within the Sonoran Desert in southern Arizona. The basin is at an altitude of $\sim 800 \mathrm{~m}$ above sea level and is surrounded by five mountain ranges that reach up to $2800 \mathrm{~m}$ above sea level. The Sonoran Desert climate has two wet seasons, due to summer monsoon rainstorms and winter frontal precipitation (SerratCapdevila et al., 2007), separated by dry periods in spring and autumn. Average annual precipitation is $300 \mathrm{~mm} \mathrm{yr}^{-1}$ (ADWR, 2010). The summer monsoons are typically localized convection storms from the south that generate short but high-intensity rainfall. In contrast, the winter fronts are driven by Pacific winds and produce rains of longer duration and lower intensity (Jurwitz, 1953). Low-atmospheric humidity and high temperatures create a water-limited environment where most of the precipitation returns to the atmosphere as evapotranspiration. Consequently, recharge in this area is limited and occurs mainly in winter as mountain front, mountain block (Wilson and Guan, 2004), diffuse, and ephemeral wash recharge (Blasch et al., 2004), with diffuse infiltration being only a minor contributor (Walvoord et al., 2002). The survey area within the basin consists of three land classes: desert ( $72 \%$ of the survey area), urban development $(27 \%)$ and agricultural land (1\%) (Fig. S1).

\section{Methods}

\subsection{Cosmic-ray rover}

The cosmic-ray rover is a mobile neutron detector similar to the stationary COSMOS probe (Zreda et al., 2012). Our unit consists of two ${ }^{3} \mathrm{He}$-filled proportional counters $7.94 \mathrm{~cm}$ in diameter and $99 \mathrm{~cm}$ in length, with a gas pressure of $152 \mathrm{kPa}$. When combined, these counters have 8.5 times the count rate of the standard ${ }^{3} \mathrm{He}$ stationary probe used in the COSMOS project (Zreda et al., 2012). The rover has three main components: a neutron detector tube, a neutron pulse module, and a data logger. When an incoming neutron collides with a ${ }^{3} \mathrm{He}$ molecule an electric charge is deposited on the center wire, and that produces a distinct and detectable pulse (Krane, 1988). That pulse is processed by the pulse module and recorded as a neutron count in the data logger. The data logger also stores GPS locations and barometric pressure. The rover is typically placed inside or on top of a truck or car. Separate sensors to monitor ambient temperature and relative humidity (Maxim iButtons, model DS1923-F5) are placed outside of the vehicle.

The stationary COSMOS probe integrates neutron counts over a sufficiently long time to produce a small uncertainty due to counting statistics. That time can be an hour or longer because soil moisture does not change quickly in time. In contrast, the integration time in the cosmic-ray rover must be short, typically one minute, to capture the average soil moisture with high spatial resolution along the path of the probe.

The footprint of the cosmic-ray rover is a swath with its width equal to the footprint of a stationary probe, and its length equal to the distance traveled during the counting interval (or averaging time). The swath width varies only slightly with soil moisture and therefore can be considered constant. The measurement depth is sensitive to the hydrogen content of the soil, and ranges from $76 \mathrm{~cm}$ for completely dry soils to $12 \mathrm{~cm}$ for saturated soils (Zreda et al., 2008). Because of the hydrogen in mineral grains (which we call lattice water) and in soil organic matter, which decreases the penetration depth of neutrons (Zreda et al., 2012), those limits are reduced to approximately $50 \mathrm{~cm}$ for dry soils (no pore water) and approximately $10 \mathrm{~cm}$ for saturated soils.

In the correction and calibration of the rover there are a few inherent assumptions of the method that are discussed in the sections to follow, but are paraphrased here. The first being the assumption that the calibration site(s) account for the heterogeneity, if any, in the surface properties of the survey area, such as lattice water, soil organic content, vegetation, and texture. We assume that the rover has minimal direction bias during data collection, meaning that highly sampled data collected on roads does not skew the true soil moisture pattern. Lastly is the assumption that there are enough sampling points throughout the survey area to generate a representative contour map of soil moisture. 


\subsection{Correction factors}

The observed neutron intensity depends on the total hydrogen in the system, which we call "total surface moisture", and the intensity of the incident neutron radiation which depends on external factors, such as solar activity (Zreda et al., 2012). To extract the signal associated with pore water, the part of the overall signal that depends on hydrogen other than that in pore water must be assessed independently. These other factors controlling neutron intensity are solar activity, barometric pressure, atmospheric water vapor pressure, lattice water, soil organic matter, and vegetation.

The intensity of the incoming, high-energy charged particles penetrating the top of Earth's atmosphere is inversely proportional to the solar activity (Zreda et al., 2012), and thus is variable in time. Because multiple surveys are used for comparison, the temporal variations in solar activity have been accounted for using the ratio $\left(f_{i}\right)$ of neutron intensity at a reference time $\left(I_{o}\right)$ to the neutron intensity at the time of the survey $\left(I_{i}\right)$ in counts per unit time:

$f_{i}=\frac{I_{o}}{I_{i}}$.

In this study, information needed to determine this correction was taken from the publicly available high-energy neutronmonitor data at http://www.nmdb.eu, station Jungfraujoch IGY. The correction should be accurate for latitude changes within 10 degrees and altitude changes within $2000 \mathrm{~m}$.

Cosmic-ray particles travel from the top of the atmosphere and are attenuated by collisions with atmospheric nuclei. A fraction of these particles eventually reaches the Earth's surface, and their abundance is inversely proportional to the total mass of air traversed (Desilets and Zreda, 2003). The mass of air above the cosmic-ray probe varies in space and time, but this can be readily assessed by monitoring barometric pressure during the surveys. In a similar manner to the neutron intensity correction, the barometric pressure correction converts the measured neutron intensity to that at a reference pressure $\left(P_{o}\right.$, in $\left.\mathrm{g} \mathrm{cm}^{-2}\right)$. The intensity decreases exponentially with increasing pressure at a rate dictated by the known (Desilets and Zreda, 2003) neutron attenuation length in air $\left(\lambda\right.$, in $\left.\mathrm{g} \mathrm{cm}^{-2}\right)$. The ratio $\left(f_{p}\right)$ of the neutron intensity at pressure $P\left(\mathrm{~g} \mathrm{~cm}^{-2}\right)$ to the neutron intensity at the reference pressure $P_{o}\left(\mathrm{~g} \mathrm{~cm}^{-2}\right)$ is (Desilets and Zreda, 2003)

$f_{p}=e^{\frac{\left(P_{o}-P\right)}{\lambda}}$.

This correction should be accurate for all pressure differences observed in a typical airborne or ground-based rover survey.

The changing hydrogen in the atmospheric water vapor is removed by calculating the contribution to the measured neutron intensity as a liquid water equivalent (Rosolem et al., 2013). The correction adjusts the measured neutron intensity to that of the reference atmospheric water vapor content

$f_{\mathrm{CWV}}=1+0.0054\left(\rho_{v}-\rho_{v}^{o}\right)$, where $f_{\mathrm{cwv}}$ is the ratio of the measured neutron intensity at a specified absolute humidity $\left(\rho_{v}\right.$, in $\left.\mathrm{g} \mathrm{m}^{-3}\right)$ to that of the reference humidity $\left(\rho_{v}^{o}\right.$, in $\left.\mathrm{g} \mathrm{m}^{-3}\right)$. This correction will be valid under all temperature and humidity ranges.

The corrected (normalized) surface moisture signal $\left(N_{\mathrm{C}}\right.$, in counts $\min ^{-1}$ ) is then calculated by the product of the reference ratios and the raw neutron intensity ( $N$, in counts $\left.\min ^{-1}\right)$ :

$N_{\mathrm{C}}=N * f_{i} * f_{p} * f_{\mathrm{CWV}}$.

In this way the effects of temporal variations in high-energy neutron intensity, barometric pressure, and water vapor are all normalized to a reference condition in the value of the corrected neutron intensity term, $N_{\mathrm{C}}$. The variability of $N_{\mathrm{C}}$ is then just a function of the main surface hydrogen stocks, specifically pore water, lattice water, vegetation and soil organic carbon which is accounted for in the site calibration.

\subsection{Calibration}

A calibration curve developed by Desilets et al. (2010) relates the corrected neutron intensity $\left(N_{o}\right)$ to the volumetric soil moisture $\theta\left(N_{\mathrm{C}}\right)$ by the calibration parameter $N_{o} . N_{o}$ will be the same everywhere if the measured neutron count rate is normalized for all factors. However, lattice water, vegetation and soil organic carbon are spatially variable. Therefore, $N_{o}$ becomes a site-specific calibration parameter that implicitly includes the effects of lattice water, vegetation, and soil organic carbon inside the cosmic-ray footprint. Measuring $N_{c}$ while independently and simultaneously measuring $\theta\left(N_{c}\right)$ allows for a computation of the calibration parameter, $N_{o} . N_{o}$ may be time variant if there are temporal variations in biomass, but this is assumed insignificant in the Tucson Basin due to the arid climate.

$\theta\left(N_{\mathrm{C}}\right)=\frac{a_{0}}{\frac{N_{c}}{N_{o}}-a_{1}}-a_{2}$,

where $a_{0}=0.0808, a_{1}=0.372, a_{2}=0.115$ (Desilets et al., 2010). For calibration, $\theta\left(N_{\mathrm{C}}\right)$ may be measured by many methods, but comprehensive soil sampling with subsequent gravimetric soil water content determination followed by oven drying is the common practice (Zreda et al., 2012). The calibration parameter $N_{0}$ remains constant in time unless there is significant vegetation change throughout the year. In space, the parameter can be determined at different locations via multiple gravimetric calibrations; alternatively, the spatially varying amount of hydrogen in lattice water, vegetation and soil organic carbon can be independently analyzed and then normalized to a constant calibration parameter.

\section{Results}

The optimal balance between interval counting time and spatial resolution resulted in a one-minute interval with a sevenminute averaging window. The instrument was calibrated at 

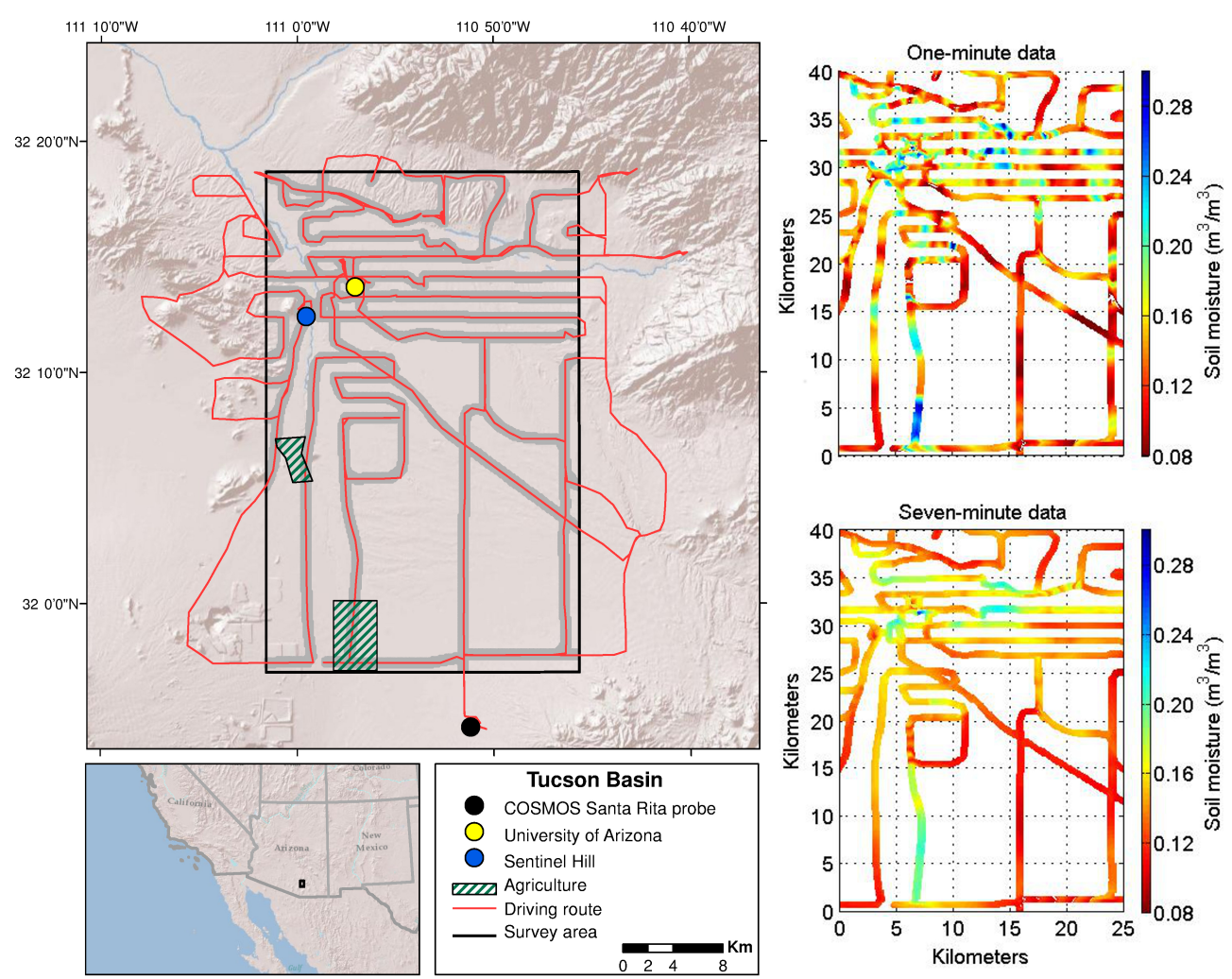

Fig. 1. Left: geographic location of the Tucson Basin and the survey area outlined in black, an example driving route shown in red with the footprint in grey and the points of interest: COSMOS probe (stationary reference), University of Arizona (wet), Sentinel Hill (dry), and agriculture (wet). Top right: one-minute soil moisture data from the 27 July 2012 survey in $\mathrm{m}^{3} \mathrm{~m}^{-3}$. Bottom right: seven-minute smoothed soil moisture data. The smoothing reduces the uncertainty due to counting statistics to $2 \%$, but increases the length of the footprint by a factor of 7 .

the Santa Rita COSMOS site. The surveys were conducted each month throughout the year, but once a week during the monsoon season (July-September) in order to capture the increased soil moisture dynamics associated with the increased precipitation in this season. We produced exploratory soil moisture maps of the survey area as snap shots in time on a $700 \mathrm{~m}$ by $700 \mathrm{~m}$ grid between latitude $31.95^{\circ} \mathrm{N}$ and $32.31^{\circ} \mathrm{N}$ and longitude $110.76^{\circ} \mathrm{W}$ and $110.03^{\circ} \mathrm{W}$. The large total number of neutron counts for each survey $\left(2 \times 10^{5}\right.$ $3 \times 10^{5}$ total counts) gave a high degree of confidence for the basin-average soil moisture value. Ancillary data was integrated with these maps to produce a daily soil moisture product as a depth-integrated value and as a depth profile. Twenty-two (22) snapshots of the soil moisture field (within one year) give insight to the climatic pattern, but they cannot be solely used to calculate the surface water fluxes that happen at a much finer timescale. Therefore, we attempt to link these patterns to daily observations in order to predict the behavior between surveys. This time-interpolation involves major assumptions, thus increasing the level of uncertainty of these results beyond errors implicit in the data. However, we think it worthwhile to provide these exploratory results for the purpose of demonstrating potential applications of the cosmic-ray rover; they are likely to improve when using alternative techniques to quantify the evolution of the daily soil moisture distribution with time. The derived soil moisture profiles were used along with independent precipitation and stream flow data to estimate the change in the moisture storage term in a mass balance calculation for the survey area. Details of these analyses are given in the following sections.

The major assumptions of the time interpolation, reconstruction of soil moisture profile, and calculation of mass balance are worth noting upfront since these are all new exploratory approaches with the capacity for further development. The time interpolation is based on point measurements to upscale the soil moisture distribution in-between rover surveys; this assumes that the dynamics behave the same through time and the point measurement accurately represents these basin dynamics. The soil moisture profile uses soil moisture information from a local TDT network to say something about the soil moisture at depth which assumes homogeneity. The profiles also use satellite data to represent the surface soil moisture. The satellite data is then adjusted based on the cosmic-ray soil moisture value, assuming a relationship between the $0-5 \mathrm{~cm}$ range and the 0 $30 \mathrm{~cm}$ range. Finally, the mass balance calculation assumes 
that the simplification of the calculation does not affect the area-average results and still provides reliable basin-wide ET estimates.

\subsection{Tucson Basin survey}

\subsubsection{Survey scheme}

The cosmic-ray rover requires a short counting interval to capture fine spatial resolution while moving, but shorter counting intervals produce fewer counts and therefore poor precision. This tradeoff between spatial resolution and measurement precision resulted in field counting for one minute, followed by computing a seven-minute moving average. This was determined to be the optimal balance resolution and precision based on the absolute count rate in the Tucson Basin. Note that the absolute count rate may be different elsewhere and other averaging windows may be more appropriate. The measurement uncertainty decreases with the number of counts $(N)$ by Poisson statistics and is computed as $N^{-0.5}$ (Zreda et al., 2012). In the survey area, a one-minute measurement yielded $\sim 400$ counts, which gave $\sim 5 \%\left(400^{-0.5}\right)$ counting uncertainty. Integrating the counts for seven minutes decreases the uncertainty to $\sim 2 \%\left(2800^{-0.5}\right)$. The moving average reduces the counting uncertainty so the variations in soil moisture dominate over statistical noise. However, this smoothing has two negative effects: it reduces local maxima and minima in soil moisture data and it produces correlated data points. The raw one-minute and seven-minute data are shown in Fig. 1, together with the geographic location of the survey area.

As mentioned in Sect. 3.1, the swath footprint is calculated by combining the stationary (circular) support volume with the distance traveled within a specified time interval, i.e., the length traveled multiplied by $600 \mathrm{~m}$ plus the stationary support volume. The average driving speed of the cosmicray rover was $55 \mathrm{~km} \mathrm{~h}^{-1}$, giving a mean footprint area of $1.7 \mathrm{~km}^{2}$, but speeds varied from near-stationary when in stopand-go city traffic to $100 \mathrm{~km} \mathrm{~h}^{-1}$ on highways, and so did the footprints. Each survey comprised $\sim 900$ data points (gathered over $\sim 900 \mathrm{~min}$ ), with a higher point density in developed areas reflecting the higher road density and lower driving speeds (Fig. 1).

\subsubsection{Calibration}

The variability of lattice water, vegetation, and soil organic carbon was investigated in the survey area. The vegetation density is low and nearly constant in the Sonoran Desert environment, and does not affect the neutron intensity significantly. Franz et al. (2013) found that vegetation with $30 \mathrm{~mm}$ of water equivalent caused an $8 \%$ reduction in neutron count rate. The Tucson Basin has an order of magnitude less vegetation, or $2 \mathrm{~mm}$, which would account for $<1 \%$ reduction of count rate, or $<4$ counts out of the av- erage of 400. Looking at these values volumetrically, $2 \mathrm{~mm}$ of vegetation water equivalent is the same as $0.005 \mathrm{~m}^{3} \mathrm{~m}^{-3}$ of soil moisture when soils are dry with water content of $0.02 \mathrm{~m}^{3} \mathrm{~m}^{-3}(2 \mathrm{~mm} / \mathrm{sensing}$ depth of $400 \mathrm{~mm}=0.005)$, and $0.01 \mathrm{~m}^{3} \mathrm{~m}^{-3}$ when soils are wet with water content of $0.20 \mathrm{~m}^{3} \mathrm{~m}^{-3}(2 \mathrm{~mm} / \mathrm{sensing}$ depth of $200 \mathrm{~mm}=0.01)$. This is the difference between barren and vegetated areas; most of the Tucson Basin area will be between these extremes, and so will be the uncertainty due to variable vegetation. Thus, we estimate that uncertainty to be less than $0.01 \mathrm{~m}^{3} \mathrm{~m}^{-3}$. The biomass in the pecan farm has not been measured due to a lack of access. However, if we assume the biomass is similar to that in the forest described in Franz et al. (2013), the neutron count could be depressed by approximately $8 \%$.

For a lattice water estimate, 16 soil samples collected within the basin were analyzed. Each sample was a composite of a subset of $\sim 50$ samples within the cosmic-ray probe footprint. The average lattice water content in the basin is $0.88 \pm 0.77$ wt. \% (wt. \% is mass of lattice water, measured at Actlabs, divided by mass of original sample multiplied by $100)$. This value is comparable to the value of $0.70 \mathrm{wt} . \% \mathrm{ob}-$ tained at the Santa Rita COSMOS probe site at the southern end of the basin (Fig. 1). In the urban area, lattice water is also found in roads, buildings and other infrastructure. We measured hydrogen content in 4 brick, 7 concrete, and 6 asphalt samples. Brick contained an upper bound of 0.68 wt. \% lattice water, asphalt samples had an upper bound of $5.10 \mathrm{wt} . \%$, and concrete samples had an upper bound of 1.52 wt. \%. The exact amount of hydrogen was not captured because a fraction was left in hydrocarbons which were not directly measured; but the mass loss on ignition at 1000 provides a constraining upper limit on that hydrogen. Brick, cement and asphalt occupy a small percentage of the support volume (horizontal extent and depth thickness) of the urban areas except for the densely built downtown; therefore we assume their lattice water signal is negligibly small. The effect of dense urbanization is unknown and needs to be investigated further, but for this study the downtown is less than one percent of the survey area and is therefore negligible.

The soil organic carbon was not analyzed throughout the basin, but assumed to be negligible because of the arid environment and the predominance of mineral soils. At the Santa Rita site soil organic carbon is $0.3 \mathrm{wt}$ \% (Zreda et al. 2012), which is roughly equal to $0.004 \mathrm{~m}^{3} \mathrm{~m}^{-3}$ of additional water (Zreda et al., 2012), a negligibly small quantity. The Santa Rita COSMOS probe served as the sole calibration site for the cosmic-ray rover used for measurements across the basin, and it is important to recognize that the results derived later depend on assuming the cosmic-ray rover calibration does not change with location and land cover. The assumption is based on the homogeneity found by the independent analysis of lattice water, vegetation, and soil organic carbon. The cosmic-ray rover was cross-calibrated against the stationary probe which had been previously calibrated against gravimetric samples. To cross-calibrate, $N_{0}$ was calculated for the 


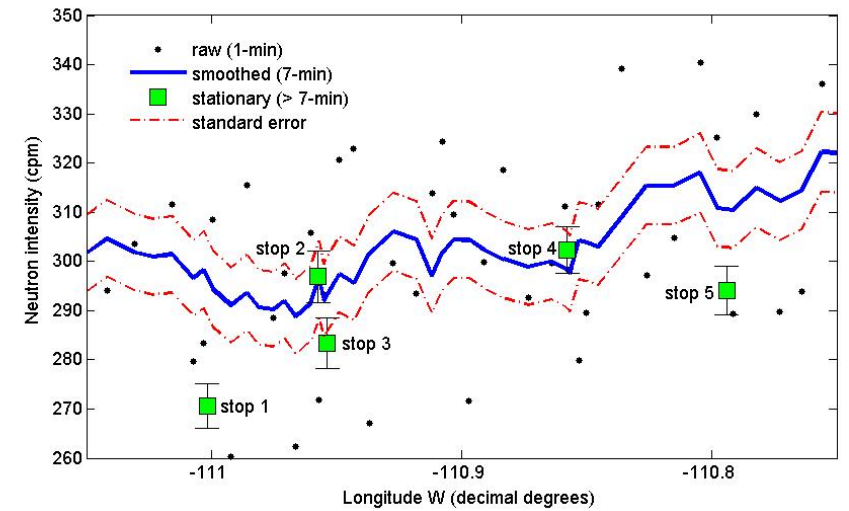

Fig. 2. Raw (one-minute), smoothed (seven-minute running averages) and stationary neutron intensity from an east-west trending transect in the Tucson Basin. The stationary points are locations where the rover was stopped; the neutron intensity was recorded for at least $7 \mathrm{~min}$ at these stops. Stops 1,3 , and 5 are small-scale features with anomalously high soil-moisture values (low neutron count rate). Stop 1 is near a golf course, stop 3 is on the University of Arizona irrigated campus, and stop 5 is at a wet spot in the foothills of the Santa Catalina Mountains.

cosmic-ray rover by using soil moisture derived from the stationary probe $\left(\theta\left(N_{c}\right)\right)$ and the neutron intensity measured and corrected with the rover $\left(N_{c}\right)$. This cross-calibration was made twice in 2012, in each case over $3 \mathrm{~h}$ to reduce the counting uncertainty to less than $1 \%$. The calibration result was also checked during each survey by stopping the rover inside the stationary Santa Rita footprint for $\sim 10-30 \mathrm{~min}$.

\subsubsection{Soil moisture maps}

When evaluating the soil moisture maps it is important to recognize systematic shortcomings in the rover survey data that are associated with driving with variable speed. As previously mentioned, when the velocity is constant at $55 \mathrm{~km} \mathrm{~h}^{-1}$ the seven-minute smoothing interval corresponds to a $6.4 \mathrm{~km}$ long swath, but the swath can be as long as $12 \mathrm{~km}$ when the speed is $100 \mathrm{~km} \mathrm{~h}^{-1}$ on the highway, or as short as a stationary circular footprint with a diameter of $600 \mathrm{~m}$ if the vehicle stops for more than seven minutes. This gives a range of swath lengths and it can also produce points that have anomalous count rates when traffic stops that are otherwise averaged out and not apparent when driving past the same point at constant speed. Figure 2 shows the neutron intensity measured while moving along an east-west transect across the Tucson Basin as one-minute raw counts and seven-minute averages, and also when the cosmic-ray rover stopped at five specific locations. The soil moisture offset from the sevenminute moving average of the mobile survey when cosmicray rover is stationary can be up to $0.10 \mathrm{~m}^{3} \mathrm{~m}^{-3}$ (e.g., at stop 1). This effect is reflected in the derived soil moisture maps in which anomalous small-scale values are consistently included in the interpolation at locations where the cosmic-

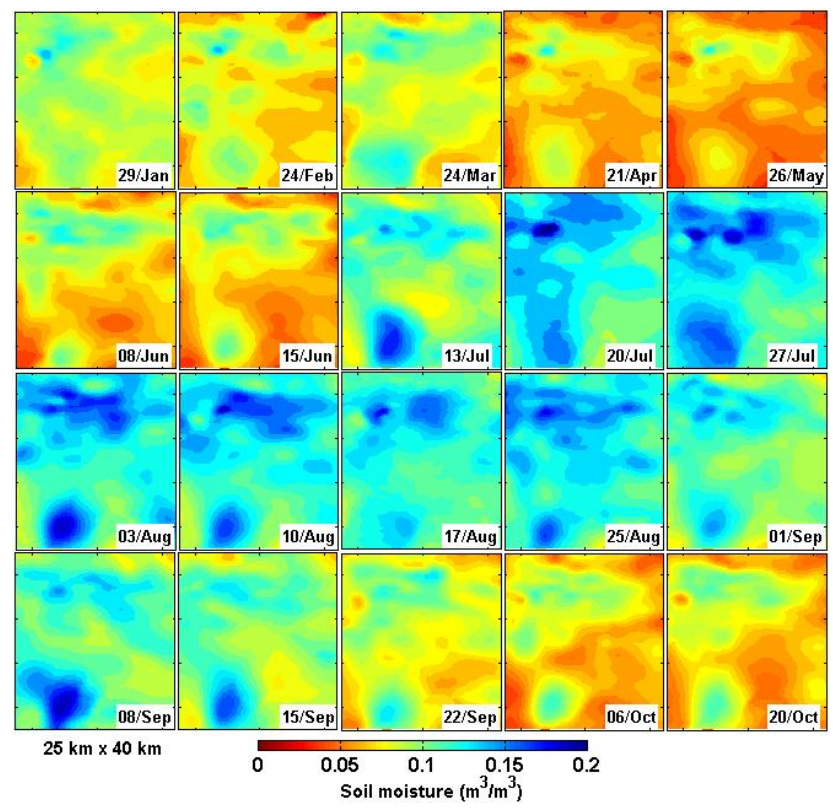

Fig. 3. Twenty interpolated soil moisture maps from seven-minute data in 2012. The urban area and agricultural fields have anomalously high soil moisture values that persist throughout the duration of the survey.

ray rover routinely stopped for longer than about seven minutes and, in particular, for stops near the University of Arizona where the soil is wetter, and Sentinel Hill where the soil is drier (see Fig. 1 for these locations). The soil moisture values recorded when stopped are of course accurate but they are only representative of the local $600 \mathrm{~m}$ diameter footprint. Other small-scale anomalies presumably also exist within the region surveyed but these are not apparent because their influence is averaged out in transit.

Other biases also exist in the maps of soil moisture that are associated with areas with low road density and bias in the direction of travel, such as in the southern part of the study region where there are few roads, and where those roads that exist have a dominant bias towards running in the northsouth direction. In such regions, error is introduced by interpolation when using the simple kriging method adopted for this study because the data is sparse. For example, the pecan farms in the southwestern part of the study area fall in a narrow strip of land but, because there are no adjacent accessible roads that allow sampling of the drier soils nearby, their wet soil signal is propagated beyond the irrigated area by the kriging algorithm. In reality, the area of influence should stop less than $300 \mathrm{~m}$ past the geographic boundaries of the agricultural sites.

Ordinary kriging was used as the interpolation technique to produce the soil moisture maps shown in Fig. 3 from the seven-minute average data for the 22 surveys. An example variogram and variogram model are shown in Fig. S3 in the Supplement. There are three main soil moisture features 
apparent in the data: (1) the distinct seasonality of soil wetness, (2) the enhanced urban soil wetness, and (3) the enhanced soil wetness of large-scale agriculture. These three features are discussed sequentially in greater detail below.

The seasonality of wetness is due to the seasonality of precipitation and air temperature. The monsoons (JulySeptember) account for more than half of the annual precipitation in Tucson (Jurwitz, 1953). During this period, the regional variance (variogram sill) of the soil moisture distribution increases from a background of $0.02-0.04\left(\mathrm{~m}^{3} \mathrm{~m}^{-3}\right)^{2}$ to $0.08-0.12\left(\mathrm{~m}^{3} \mathrm{~m}^{-3}\right)^{2}$, except for the anomalously high variance in March. This anomaly is attributed to the recent winter rain event. In general, the degree of regional variance across the basin increasing as the mean soil moisture increases which is observed in a variogram analysis in time. The correlation length scale, which ranges between 1.5 and $5.5 \mathrm{~km}$, does not show the same pattern and does not seem to be related to precipitation nor the mean soil moisture. During the monsoon season, the soil moisture enters into a more dynamic state due to fast wetting from monsoon precipitation and then fast drying due mainly to evaporation. This seasonal moisture effect is seen in the survey maps from as a relative shift in soil moisture (Fig. 3) with a corresponding increase in regional variance and similarly, an increase in the standard deviation (Table S1).

The urban wetness is clearly visible in all maps (Fig. 3). The northern part of the survey area is predominantly a developed urban area (Fig. S1). This urbanization is observed to create a moisture oasis in the drier surrounding Sonoran Desert. Adding urban landscaping (parks, gardens, lawns, etc.) causes more moisture to be added to the environment by irrigation. The soil moisture in the urban landscape is consistently wetter than the natural landscape, regardless of the season.

Increased soil wetness is apparent in two areas of irrigated agriculture in the survey area, both along the Santa Cruz Wash that runs north to south on the west side of the basin. The first is the San Xavier Indian Reservation in the west-central side of the basin and the more prominent region is the Green Valley pecan farms at the southern end of the survey area. The pecan farm is a large flood-irrigated plot that remains wetter than the surrounding desert landscape by $\sim 0.03-0.07 \mathrm{~m}^{3} \mathrm{~m}^{-3}$ and up to $0.10 \mathrm{~m}^{3} \mathrm{~m}^{-3}$ when surface ponding was present.

In comparison with previous soil moisture distribution studies, the standard deviation was plotted against the mean soil moisture (Fig. 4) using the relationship in Famiglietti et al. (2008)

$\sigma=k_{1} * \theta_{\text {mean }} * e^{\left(k_{2} * \theta_{\text {mean }}\right)}$,

where $\sigma$ is the standard deviation $\left(\mathrm{m}^{3} \mathrm{~m}^{3}\right), \theta_{\text {mean }}$ is the spatial mean soil moisture $\left(\mathrm{m}^{3} \mathrm{~m}^{-3}\right)$, and $k_{1}$ and $k_{2}$ are the fitting parameters. This specific functional form was chosen as it seems to fit the data within the observed range

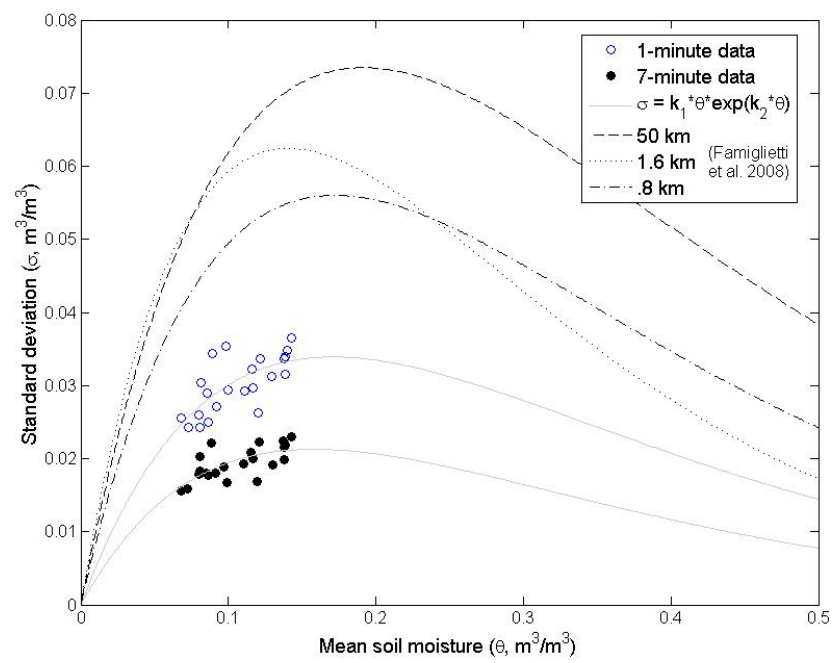

Fig. 4. Mean soil moisture versus the standard deviation for oneminute data and the seven-minute running averages. The pattern is consistent with Famiglietti et al. (2008), but it has smaller magnitude due to the area-average and depth integrated nature of the cosmic-ray support volume.

and therefore as an example to estimate the standard deviation from the mean. The estimation is required in the time interpolation discussed in the following section. The mean soil moisture in the survey area was only captured between 0.07 and $0.16 \mathrm{~m}^{3} \mathrm{~m}^{-3}$; therefore it does not display the full convex upward behavior, but does fit the function in this range. Other functional forms may provide a better fit, but only observational data at the extremes will be able to determine that. The magnitude of the variability was shown to increase with spatial extent; up to $0.07 \mathrm{~m}^{3} \mathrm{~m}^{-3}$ for the $50 \mathrm{~km}$ scale. In our data, we observe the one-minute data reaching a maximum standard deviation of $0.03 \mathrm{~m}^{3} \mathrm{~m}^{-3}$ and the seven minute data reaching $0.02 \mathrm{~m}^{3} \mathrm{~m}^{-3}$. The seven-minute smoothing decreases the overall variability by averaging out anomalous small-scale features along with inherent noise, shown as a downward translation in Fig. 4 and described in further detail in the following section.

\subsection{Time interpolation}

Previous studies have shown temporal stability in soil moisture (Cosh et al., 2004; Martinez-Fernandez and Ceballos, 2003; Vachaud et al., 1985) and have reported that the spatial variance may be related to the mean soil moisture (MartinezFernandez and Ceballos, 2003; Western et al., 2004). Temporal stability in the spatial patterns indicate that the soil moisture distribution acts in a systematic way dominated by persistent surface and atmospheric characteristics and processes. In the survey area, we observe stability in that the high soil moisture regions remain consistently high and the low soil moisture regions remain consistently low. In this section, we attempt to quantify this temporal stability and incorporate it 

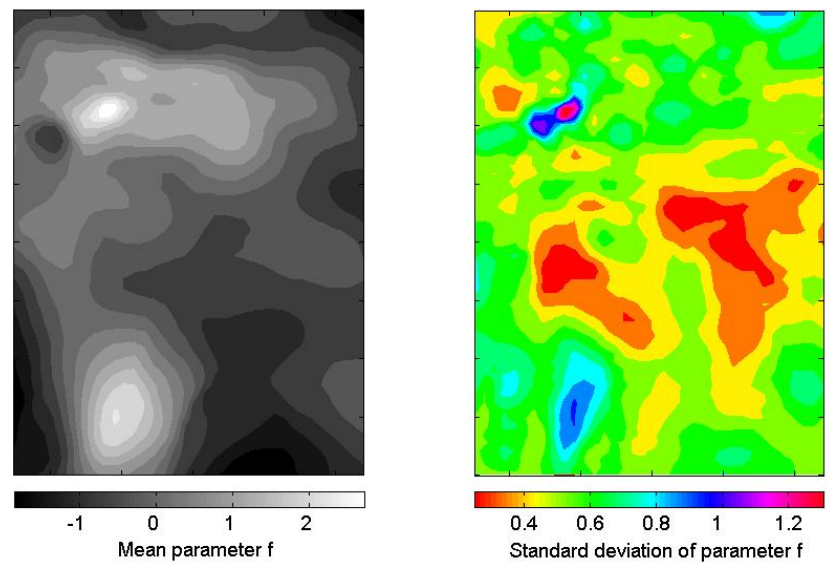

Fig. 5. Left: the spatial structure map in the $25 \times 40 \mathrm{~km}$ survey area of the mean parameter $f$ from the 22 cosmic-ray rover surveys. Right the standard deviation map of the parameter $f$ values.

into the modeling of the daily soil moisture distributions. To do this, we calculated the offset of each cell $(700 \times 700 \mathrm{~m})$ from the mean soil moisture $\left(\theta_{\text {mean }}\right)$ as a fraction $(f)$ of the basin-wide standard deviation $(\sigma)$

$\theta_{\text {cell }}=\theta_{\text {mean }}+f * \sigma$,

where $\theta_{\text {mean }}$ and $\sigma$ are in units of $\mathrm{m}^{3} \mathrm{~m}^{-3}$. The standard deviation is derived from the exponential form outlined in Eq. (6), which was fitted to our seven-minute data (Fig. 4). The $f$ parameter remains relatively constant in time as indicated by the temporal standard deviation, validating the statement of temporal stability. The mean of the spatially varying $f$ parameter and its standard deviation from the 22 maps surveys is shown in Fig. 5. The standard deviation of the $f$ parameter is fairly low except for the pecan farms due to irregular irrigation, and for the anomalously wet University of Arizona and anomalously dry Sentinel Hill. Equation (7) relies on two conditions, that the soil moisture distribution displays temporal stability in the spatial patterns and that the exponential relationship between the mean soil moisture and the standard deviation is defined correctly; both seem to be satisfied for our data set. In Fig. 6 we show the reproduced soil moisture distributions of the 22 survey days from the $f$ parameter and mean soil moisture from surveyed data. The maps are very similar to the cosmic-ray rover surveys (Fig. 2) because of a high degree of temporal stability indicated by an average correlation coefficient of 0.82 ; however, we conclude that this approach is accurate only if the basin-wide mean soil moisture is defined correctly. Absolute difference maps between the surveys and the modeled results are shown in the Supplement Fig. S2. Note that in these reproduced maps the spatial pattern does not change since the mean of the $f$ parameters data was used.

The challenge in modeling this distribution at the daily time step is having an accurate representation of the mean soil moisture from an independent measurement. The Santa

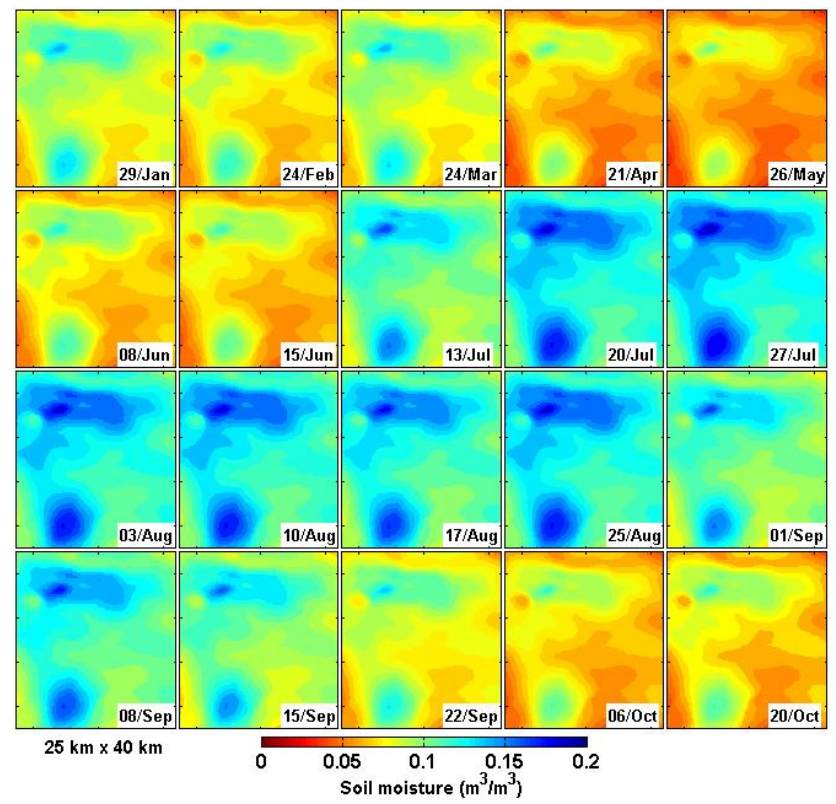

Fig. 6. The modeled soil moisture maps from 2012 using the relationship in Eq. (7). The same overall trend is preserved when the mean soil moisture is constrained. The pattern is consistent because the mean $f$ parameter was used to reproduce each map result.

Rita COSMOS point measurement served as our reference data, as it is highly correlated with the basin-wide mean. Daily soil moisture maps were produced from the year 2012 based on Eqs. (6)-(7) and the correlation between the basin mean and the Santa Rita COSMOS probe shown in Fig. 7. Figure 7 displays two linear regressions, one assigned for the winter months (January-April) and another for the drysummer and monsoonal months (May-December). The regression functions have an $r^{2}$ of 0.84 and 0.91 giving a reliable fit, suggesting that the relationship between the Santa Rita probe and the basin-wide mean soil moisture changes with season and when different atmospheric and surface processes dominate. We hypothesize that the difference in elevation and soil texture accentuate the difference in soil moisture behavior with increasing wetness, and since the seasons are characterized by wetness, seasonality becomes a major factor. Water management activities may impact this regression to some degree, but the effect is unknown at this time. In the data set, it is seen as abrupt shift in the estimated mean soil moisture (Fig. 9, top panel). This transition is not well captured with the current method and is considered a processing artifact; however the rest of the data set matches the survey results within $0.02 \mathrm{~m}^{3} \mathrm{~m}^{-3}$ uncertainty. 


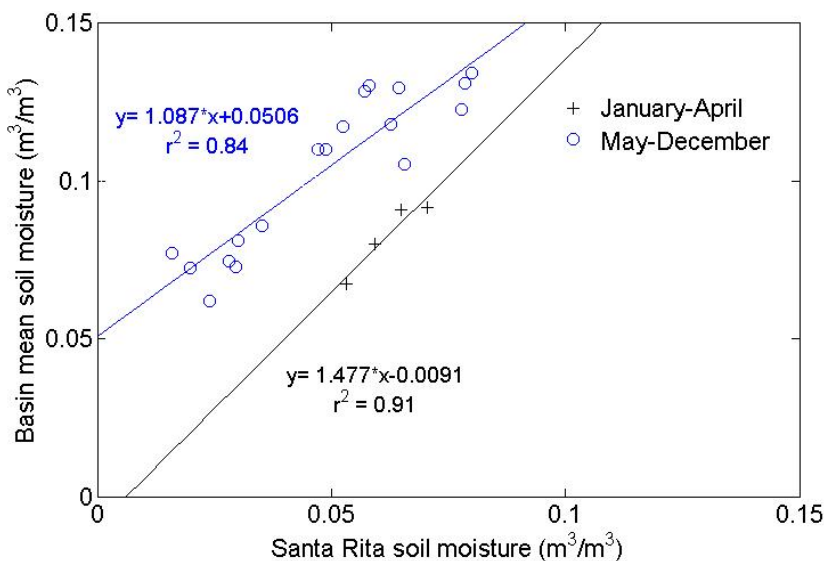

Fig. 7. The correlation between the mean soil moisture from the 22 cosmic-ray rover surveys with the corresponding soil moisture from the Santa Rita COSMOS point measurement. The correlation changes with season and is approximated by separating the winter months (January-April) from the dry season and monsoon (MayDecember) surveys.

\subsection{Basin-wide hydrologic application}

\subsubsection{Soil moisture profile}

Soil moisture profiles are not necessarily uniform and a single sample value of a portion of the profile (which is the case for the cosmic-ray rover) may not accurately represent the soil water storage in a near-surface water balance. To improve the storage estimate, we developed an integrated approach using the cosmic-ray rover and satellite measurements to estimate an area-average soil-moisture profile. This approach is similar to that used in remote sensing, where satellite retrievals have utilized different wavelengths that penetrate to different depths (Jackson, 1980; Reutov and Shutko, 1990), although all have been limited to the top $5 \mathrm{~cm}$ (Laymon et al., 2001). Our approach uses information from three depths in the soil column to generate soil moisture profiles: (1) a surface measurement (from satellite-based microwave instrument, $0-5 \mathrm{~cm}$ ), (2) a deeper measurement (from cosmic-ray rover, $10-50 \mathrm{~cm}$ ), and (3) a constraining value at depth. In our analysis the cosmic-ray rover measurements are averaged in space to the size of the Soil Moisture and Ocean Salinity (SMOS) level 3 products which we take as the surface measurement (http://catds.ifremer.fr/).

The cosmic-ray probe's penetration depth was recently derived by Franz et al. (2012) where the soil moisture, bulk density, and lattice water determine the depth from which $86 \%$ of the neutrons are sourced. Franz et al. (2012) also approximated how much each layer contributes to the overall signal by a linear weighting function. This integrated measurement is converted to a point on the soil moisture profile by assign-

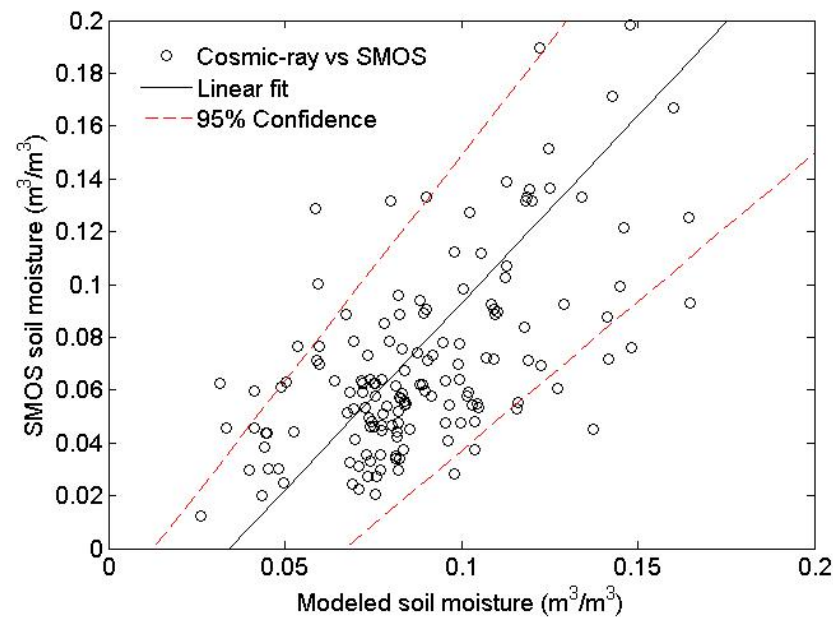

Fig. 8. Correlation of the area-average SMOS Level 3 soil moisture product with the interpolated cosmic-ray soil moisture values. The correlation is described here with and linear relationship. The SMOS product has a significant degree of noise $\left(\sim 0.04 \mathrm{~m}^{3} \mathrm{~m}^{-3}\right)$, and in consequence was reprocessed with this correlation. The scatter is attributed to satellite noise and uncertainties in the interpolation.

ing it the centroid of the weighting function $(C, \mathrm{~cm})$

$C=\frac{1}{3} z^{*}$

where $z^{*}$ is the penetration depth in $\mathrm{cm}$. The centroid is computed as $1 / 3$ of $z^{*}$ because the linear weighting function creates a right triangle with the weight of the surface layer as the horizontal leg and the depth of penetration as the vertical leg. The centroid depth is the most representative point of the soil column to assign the cosmic-ray measurement.

Data from 190 TDT probes installed at the Santa Rita stationary COSMOS site (Franz et al., 2012b) show no significant change in soil moisture below the depth of $40 \mathrm{~cm}$, which is consistent with previous observations that diffuse recharge at the basin floor is minimal (Walvoord et al., 2002). Because the daily dynamics of soil moisture at $40 \mathrm{~cm}$ depth is so slow, when synthesizing the area average profile we assume the soil moisture at this depth is constant and assigned the value $0.06 \mathrm{~m}^{3} \mathrm{~m}^{-3}$, consistent with the TDT data. $40 \mathrm{~cm}$ was chosen as a depth of minimal daily soil moisture changes from the TDT data, not specific to the depth of penetration of the cosmic-ray rover. This exploratory exercise may not be applicable everywhere. In wetter areas where soil infiltration and recharge are significant, the soil moisture value at depth may not be so easily constrained. In addition, the TDT network is a point measurement and carries the uncertainty that the deep soil moisture behavior at the point may not be representative of the rest of the survey area.

In common with other satellite microwave sensors, the SMOS signal has substantial noise due to the influence on the measurement of variables other than moisture (Entekhabi 


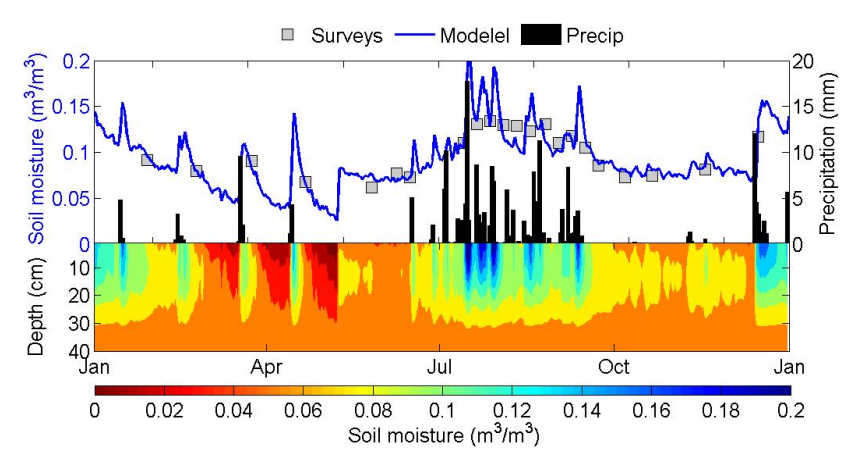

Fig. 9. Top: time-interpolated soil moisture (blue line) generated from the modeled results where the mean soil moisture was estimated from the Santa Rita COSMOS point measurement. Precipitation amounts are shown as black bars and rover surveys as gray boxes. Bottom: soil moisture profiles generated from three depth points. The abrupt shift in the mean soil moisture is due to the change in the linear regression relationship from winter to summer and is an artifact in the result.

et al., 2004; Kerr et al., 2010). Nevertheless, it still captures the same trend seen with the interpolated cosmic-ray measurement defined by a linear function (Fig. 8). In order to limit noise propagating through the storage terms and also to fill the time gaps, the surface value was re-calculated based on the linear function with a given cosmic-ray measurement. The re-calculated surface value was then used as the surface input in the profile calculation. This relationship is an ad hoc solution to estimate the top layer soil moisture and has a larger bias to the cosmic-ray integrated value. Any improvements in the accuracy of satellite measurements will improve the robustness of this approach, but at this time we believe the satellite data is too noisy to be used as a stand-alone product in this application. The computed soil moisture profiles are shown in the bottom panel of Fig. 9. As mentioned in the previous section, the top panel shows the modeled basinwide mean with precipitation and the cosmic-ray rover survey means.

\subsubsection{Mass balance}

A mass balance is computed to provide estimates of evapotranspiration loss and to explore the possible use of the cosmic-ray rover as a tool in adding closure to a basin-wide mass balance. The mass balance outlined here serves as the survey area average including all land cover types. The mass balance calculation is defined (see, for example, Freeze and Cherry, 1979) by the equation

$\mathrm{ET}(t)=P(t)-R(t)-\Delta S_{\text {soil }}(t)-\Delta S_{\text {ground }}(t)$,

where ET is evapotranspiration at time $t, P$ is precipitation, $R$ is runoff, $\Delta S_{\text {soil }}$ is the change in soil moisture storage, and $\Delta S_{\text {ground }}$ is the change in groundwater storage; all terms are in $\mathrm{mm} \mathrm{day}^{-1}$ per unit area. As discussed in Sect. 2, there is minimal diffuse recharge, and wash recharge is orders of magnitude less than evapotranspiration. The regional groundwater flow is also negligible compared to the evapotranspiration flux (Kalin, 1994). Therefore, $\Delta S_{\text {ground }}$ is negligible and the equation reduces to

$\mathrm{ET}(t)=P(t)-R(t)-\Delta S_{\text {soil }}(t)$.

Runoff was calculated from the inlet and outlet gauges using the publicly available United States Geological Survey's (USGS) stream gauge network (http://waterdata.usgs.gov/ nwis/rt) and the Pima County Flood Control's (PCFC) Alert system (http://alert.rfcd.pima.gov), but was found to have a negligible contribution to the mass flux and is taken as zero here.

The soil moisture profiles are used to calculate change in storage. The integral is calculated at each time step to calculate the soil moisture storage $\left(S(t)\right.$, in $\left.\mathrm{mm} \mathrm{day}^{-1}\right)$,

$\Delta S(t)=\int_{0}^{z_{d}} \theta(z) \mathrm{d} z-S_{t-1}$,

where $\Delta S(t)$ is the change in storage $\left(\mathrm{mm} \mathrm{day}^{-1}\right), \theta(z)$ is the soil moisture in $\mathrm{m}^{3} \mathrm{~m}^{-3}$ at depth $z(\mathrm{~mm})$ at time $t$, and $z_{d}$ $(\mathrm{mm})$ is the base of the estimated profile, set to $400 \mathrm{~mm}$.

Precipitation is gridded for the basin using 104 rain gauges from the publicly available Rainlog Network (rainlog.org) and the PCFC's Alert system with a linear interpolation. The basin-wide average precipitation events in 2012 had magnitudes between 3 and $15 \mathrm{mmday}^{-1}$, with a yearly total of $224 \mathrm{~mm}$. The rain gauge network is denser in the developed areas of Tucson than in the less developed areas in the south side of the Tucson Basin, and consequently has greater confidence. The uncertainty is expressed in the cumulative distribution plot in Fig. 10; the gray shaded region represents the difference between the basin-wide precipitation based on the Rainlog network and the ALERT network; the average precipitation is shown as the black line.

ET is calculated daily from Eqs. (9)-(11) from a uniform profile down to $70 \mathrm{~cm}$ and the derived soil moisture profiles from the previous section to investigate if the soil moisture profiles improve the mass flux calculation. These are shown in Fig. 10 where the ET from the estimated profile behaves much more reasonably than the uniform profile, which tends to overestimate the near-surface mass flux. The ET curves show a decrease after a rain event, because of the coarse time resolution. The average daily soil moisture shows the increase in precipitation typically the day after the event since the soil moisture during the event is averaged out with the soil moisture on the previous day. Also, the uniform case shows large decreases in ET that is unrealistic since the soil moisture increases are much greater than the precipitation event itself. The abrupt change in the ET curves is again due to the change in regression from the Santa Rita probe when attempting to estimate the basin-wide mean soil moisture. In 

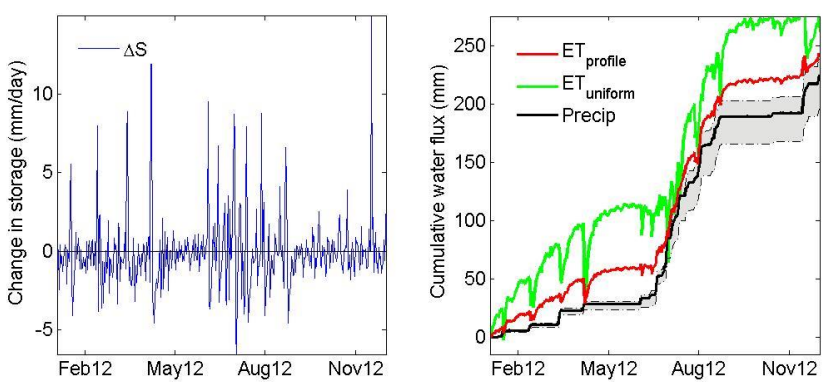

Fig. 10. Left: the change in soil moisture storage in $\mathrm{mm}$ per day. Right: cumulative distribution in time of precipitation (Precip), ET estimated from the soil moisture profiles $\left(\mathrm{ET}_{\text {profile }}\right)$ and uniform

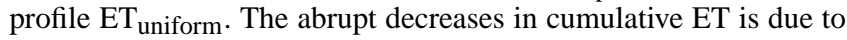
a time discrepancy between precipitation events and daily average soil moisture values.

summary, the mass balance gives insight into how the interpolation and profile estimate techniques are performing. The value of ET derived from the profile seems to constrain the soil moisture change to values more realistic of system and the cosmic-ray rover provides a new observation technique to measure it.

\section{Conclusions}

This paper outlines a new approach which shows new potential to generate soil moisture maps at the mesoscale between the satellite products and point measurements with the cosmic-ray rover. The following list summarizes the main points of the paper:

- Measurements of cosmic-ray neutrons with the cosmic-ray rover yielded soil moisture maps in the survey area $(25 \mathrm{~km} \times 40 \mathrm{~km})$ at an interpolated resolution of $\sim 1 \mathrm{~km}$.

- Temporal stability in the spatial patterns is observed; this is hypothesized to be a result of reoccurring processes, fixed surface characteristics, and water management activities.

- If temporal stability exists, an estimate of the soil moisture distribution may be more accurately modeled by upscaling or downscaling by quantifying the temporal stability as a function of the spatial mean and spatial standard deviation.

- Integrating cosmic-ray rover measurements with satellite products may allow for an improved estimate of the soil moisture profile, and therefore an improvement in catchment scale mass balance.

The observed temporal stability of soil moisture in the survey area may or may not be present elsewhere. This deserves further investigation. Future work should determine how to calibrate the cosmic-ray rover for vegetation, lattice water, and soil organic carbon. Interpolation techniques can also be improved to constrain the observations to land cover information, such as the outline of the pecan farm or other increased areas of wetness. In terms of spatial structure and the predictability, the functional form in Eq. (6) (Famiglietti et al., 2008) and the $f$ parameter in Eq. (7) should be investigated to find out how universal or variable these relationships are at this scale. For hydrologic applications, the ET estimates and soil moisture profiles need to be validated with robust data sets, such as distributed eddy covariance towers within the survey area. The mass balance study in Sect. 4 is an example of the potential use of the cosmic-ray rover but is currently only an exploratory method to investigate the catchment scale hydrology. The main objective of this paper was to provide a methodological approach for the cosmicray rover and an example data set of mesoscale soil moisture maps.

\section{Supplementary material related to this article is available online at http://www.hydrol-earth-syst-sci.net/ 17/5097/2013/hess-17-5097-2013-supplement.pdf.}

Acknowledgements. This research was part of the COSMOS project, funded by the Atmospheric Science, Hydrology, and Ecology Programs of the US National Science Foundation (grant ATM-0838491). The fundamental work on the systematics of low-energy neutrons on earth was funded by the US National Science Foundation (grants EAR-0345440 and EAR-0636110). We thank Quaesta Instruments and Hydroinnova for designing the COSMOS rover to satisfy the needs of the project. Jim Shuttleworth, Xubin Zeng, Trenton Franz and Ahmad Al Bitar provided useful discussions that improved the paper. Students at the University of Arizona contributed to field and laboratory operations. We also thank the Centre Aval de Traitement des Données SMOS" (CATDS), operated for the "Centre National d'Etudes Spatiales" (CNES, France) by IFREMER (Brest, France) for providing the SMOS Level 3 data. We thank Heye Bogena and Hilary Mcmillan, who reviewed the paper, and Jim Freer, the HESS editor, whose thoughtful comments improved the paper.

Edited by: J. Freer

\section{References}

Arizona Department of Water Resources, (ADWR): Arizona Water Atlas, in: Active Management Area Planning Area, 2010.

Blasch, K., Ferré, T. P. A., Hoffmann, J., Pool, D., Bailey, M., and Cordova, J.: Processes Controlling Recharge Beneath Ephemeral Streams in Southern Arizona, in: Groundwater Recharge in a Desert Environment: The Southwestern United States, American Geophysical Union, 69-76, 2004.

Bogena, H. R., Herbst, M., Huisman, J. A., Rosenbaum, U., Weuthen, A., and Vereecken, H.: Potential of Wireless Sensor Networks for Measuring Soil Water Content Variability, Vadose Zone J., 9, 1002-1013, doi:10.2136/vzj2009.0173, 2010. 
Cosh, M. H., Jackson, T. J., Bindlish, R., and Prueger, J. H.: Watershed scale temporal and spatial stability of soil moisture and its role in validating satellite estimates, Remote Sens. Environ., 92, 427-435, doi:10.1016/j.rse.2004.02.016, 2004.

Desilets, D. and Zreda, M.: Spatial and temporal distribution of secondary cosmic-ray nucleon intensities and applications to in situ cosmogenic dating, Earth Planet. Sci. Lett., 206, 21-42, doi:10.1016/s0012-821x(02)01088-9, 2003.

Desilets, D. and Zreda, M.: Footprint diameter for a cosmic-ray soil moisture probe: Theory and Monte Carlo simulations, Water Resour. Res., 49, 3566-3575, doi:10.1029/wrcr.20187, 2013.

Desilets, D., Zreda, M., and Ferre, T. P. A.: Nature's neutron probe: Land surface hydrology at an elusive scale with cosmic rays, Water Resour. Res., 46, W11505, doi:10.1029/2009wr008726, 2010.

Entekhabi, D., Njoku, E. G., Houser, P., Spencer, M., Doiron, T., Kim, Y. J., Smith, J., Girard, R., Belair, S., Crow, W., Jackson, T. J., Kerr, Y. H., Kimball, J. S., Koster, R., McDonald, K. C., O’Neill, P. E., Pultz, T., Running, S. W., Shi, J. C., Wood, E., and van Zyl, J.: The hydrosphere state (Hydros) satellite mission: An earth system pathfinder for global mapping of soil moisture and land freeze/thaw, IEEE Trans. Geosci. Remote Sens., 42, 2184 2195, doi:10.1109/tgrs.2004.834631, 2004.

Famiglietti, J. S., Ryu, D. R., Berg, A. A., Rodell, M., and Jackson, T. J.: Field observations of soil moisture variability across scales, Water Resour. Res., 44, W01423, doi:10.1029/2006wr005804, 2008.

Franz, T. E., Zreda, M., Ferre, T. P. A., Rosolem, R., Zweck, C., Stillman, S., Zeng, X., and Shuttleworth, W. J.: Measurement depth of the cosmic ray soil moisture probe affected by hydrogen from various sources, Water Resour. Res., 48, W08515, doi:10.1029/2012wr011871, 2012.

Franz, T. E., Zreda, M., Rosolem, R., Hornbuckle, B. K., Irvin, S. L., Adams, H., Kolb, T. E., Zweck, C., and Shuttleworth, W. J.: Ecosystem scale measurements of biomass water using cosmic-ray neutrons, Geophys. Res. Lett., 40, 3929-3933, doi:10.1002/grl.50791, 2013.

Freeze, R. A. and Cherry, J. A.: Groundwater, Prentice Hall, Englewood Cliffs, N. J., 1979.

Jackson, T. J.: Profile soil-moisture from surface measurements, J. Irrig. Drain. Divis.-Asce, 106, 81-92, 1980.

Jurwitz, L. R.: Arizona's Two-Season Rainfall Pattern, Weatherwise, 6, 96-99, doi:10.1080/00431672.1953.9932951, 1953.

Kalin, R. M.: The hydrogeochemical evolution of the groundwater of the Tucson basin with application to 3 dimensional groundwater flow modelling, Department of Geosciences, University of Arizona, 1994.

Kerr, Y. H., Waldteufel, P., Wigneron, J. P., Delwart, S., Cabot, F., Boutin, J., Escorihuela, M. J., Font, J., Reul, N., Gruhier, C., Juglea, S. E., Drinkwater, M. R., Hahne, A., Martin-Neira, M., and Mecklenburg, S.: The SMOS Mission: New Tool for Monitoring Key Elements of the Global Water Cycle, Proc. IEEE, 98, 666687, doi:10.1109/jproc.2010.2043032, 2010.

Krane, K. S.: Introductory nuclear physics: New York, Wiley, p. $845,1988$.

Larson, K. M., Small, E. E., Gutmann, E. D., Bilich, A. L., Braun, J. J., and Zavorotny, V. U.: Use of GPS receivers as a soil moisture network for water cycle studies, Geophys. Res. Lett., 35, L24405, doi:10.1029/2008g1036013, 2008.
Laymon, C. A., Crosson, W. L., Jackson, T. J., Manu, A., and Tsegaye, T. D.: Ground-based passive microwave remote sensing observations of soil moisture at S-band and L-band with insight into measurement accuracy, IEEE Trans. Geosci. Remote Sens., 39, 1844-1858, doi:10.1109/36.951075, 2001.

Martinez-Fernandez, J. and Ceballos, A.: Temporal stability of soil moisture in a large-field experiment in Spain, Soil Sci. Soc. Am. J., 67, 1647-1656, 2003.

Reutov, E. A. and Shutko, A. M.: Microwave spectroradiometry of water content of nonuniformly moistened soil with a surface transition layer, Sov. J. Remote Sens., 6, 72-79, 1990.

Robinson, D. A., Campbell, C. S., Hopmans, J. W., Hornbuckle, B. K., Jones, S. B., Knight, R., Ogden, F., Selker, J., and Wendroth, O.: Soil moisture measurement for ecological and hydrological watershed-scale observatories: A review, Vadose Zone J., 7, 358389, doi:10.2136/vzj2007.0143, 2008.

Rosolem, R., Zreda, M., Franz, T. E., and Zeng, X.: The effect of atmospheric water vapor on the cosmic-ray soil moisture signal, J. Hydrometeorol., 14, 1659-1671, doi:10.1175/JHM-D-120120.1, 2013.

Serrat-Capdevila, A., Valdes, J. B., Perez, J. G., Baird, K., Mata, L. J., and Maddock, T.: Modeling climate change impacts and uncertainty on the hydrology of a riparian system: The San Pedro Basin (Arizona/Sonora), J. Hydrol., 347, 48-66, doi:10.1016/j.jhydrol.2007.08.028, 2007.

Vachaud, G., Desilans, A. P., Balabanis, P., and Vauclin, M.: Temporal stability of spatially measured soil-water probability densityfunction, Soil Sci. Soc. Am. J., 49, 822-828, 1985.

Walvoord, M. A., Plummer, M. A., Phillips, F. M., and Wolfsberg, A. V.: Deep arid system hydrodynamics - 1. Equilibrium states and response times in thick desert vadose zones, Water Resour. Res., 38, 1308, doi:10.1029/2001wr000824, 2002.

Western, A. W. and Bloschl, G.: On the spatial scaling of soil moisture, J. Hydrol., 217, 203-224, doi:10.1016/s00221694(98)00232-7, 1999.

Western, A. W., Zhou, S. L., Grayson, R. B., McMahon, T. A., Bloschl, G., and Wilson, D. J.: Spatial correlation of soil moisture in small catchments and its relationship to dominant spatial hydrological processes, J. Hydrol., 286, 113-134, doi:10.1016/j.jhydrol.2003.09.014, 2004.

Wilson, J. L. and Guan, H.: Mountain-Block Hydrology and Mountain-Front Recharge, in: Groundwater Recharge in a Desert Environment: The Southwestern United States, Am. Geophys. Union, 113-137, 2004.

Zreda, M., Desilets, D., Ferre, T. P. A., and Scott, R. L.: Measuring soil moisture content non-invasively at intermediate spatial scale using cosmic-ray neutrons, Geophys. Res. Lett., 35, L21402, doi:10.1029/2008g1035655, 2008.

Zreda, M., Shuttleworth, W. J., Zeng, X., Zweck, C., Desilets, D., Franz, T. E., and Rosolem, R.: COSMOS: the COsmic-ray Soil Moisture Observing System, Hydrol. Earth Syst. Sci., 16, 40794099, doi:10.5194/hess-16-4079-2012, 2012. 